\section{An Introduction to the Theory of Relativity}

By Dr. W. G. V. Rosser. Pp. xiv + 516. (London: Butterworth and Co. (Publishers), Ltd., 1964.) $75 s$.

$\mathrm{N}$ the past, books on special relativity havo fallen into I two distinct groups. There are some meant primarily for mathematicians which are exhaustive discussions in which the experiments take a back seat and the more abstract parts of the theory are fully developed. Now that the special theory is so well established, there is an important part for such books to play. The fact remains that undergraduates reading physics are not well catered for by these books, and those treatments of the subject which are more slantod towards physicists are all small light-weight accounts. Accordingly, An Introduction to the Theory of Relativity meets an important need and it ines so magnificently. There can seldom have been such a complete justification for special rolativity in terms of experimental results. Every important confirmation of the theory is fully dealt with and discussed in a simple and enlightening way.

The book begins with two chapters of historical introduction, one dealing with mechanics and one with the theories of the ether. The Lorentz transformations are then introdueed on the basis of a constant velocity of light, and in the next two chapters their consequences in opties and mochanies are fully discussed. The author then goes over to the use of a four-dimensional representation and uses this to begin his discussion of electromagnetism, starting with the formula for a force between currents. After a fairly conventional treatment of Maxwell's equations, the author devotes a whole chapter to the elock paradox and criticism of special relativity. A concluding chapter gives an intuitive account of general relativity without going into the whole mathematical theory. There is an excellent bibliography and a very full index.

\section{W. Kilmister}

\section{Guide to Activation Analysis}

Edited by William S. Lyon, Jun. Pp. xix +186 . (Princeton, N.J., and London: D. Van Nostrand Company, 1964.) 46s. $6 d$.

UIDE to Activation Analysis describes the major aspects of activation analysis in eight chapters by different authors: two appendixes givo calculated sensitivities and safety and licensing requirements. The first two chapters deal with basic nuclear properties and with reactor neutron flux characteristics, non-reactor neutron sources are then described and compared, and there is a short chapter on the subject of radiochemical separations. Various aspects of counting are considered in two further chapters, less widely applied techniques such as charged particle and $\gamma$-photon activation are then described by the Editor himself, and the final chapter is devoted to practical examples of activation analysis.

At a time when intact methods of analysis are becoming more widely applied, the chapter on scintillation counting techniques provides a useful introduction to instrumental methods, and the short section on semiconductor particle detectors is also most topical. It is unfortunate, however, that radiochemical separations, still a very important part of activation analysis, are not more fully discussed.

Valuable information is included in the second chapter on the measurement and application of epithermal and fast reactor neutron fluxes, and Appendix 1 contains a comprehensive bibliography of determinations carried out by activation analysis.

This is a useful book and when used in conjunction with the references quoted it will enable thoso interested in applying activation analysis to gain a satisfactory basis for their work.

T. B. PIERCE

\section{Matrices}

Their Meaning and Manipulation. By Prof. W. G. Bickley and R.S. H. G. Thompson. (General Engineering Series.) Pp. xiii +168 . (London: The English Univorsities Press, Ltd., 1964.) 21s. net.

THIS book shows clearly how to present a difficult topic in a concise and interesting mannor. The authors have used their great didactic skill in securing tho co-operation of the reader, not only by appealing to his sense of purpose, but also by encouraging him to solve numerous problems which supplement the text.

Few would disagree that modern engineers ought to have a rudimentary knowledge of matrices. It is encouraging to see a text which strikes just the right balance between theory and application, includes numerical examples and gives a discussion of pitfalls awaiting the unwary. The book, appropriately enough, starts with a brief description of numerous present-day applications of matrices, both in engineering and in physics. This is followed by a brief exposition of matrix notation, matrix multiplication and its applications, and an introduction to the theory of determinants. The four final chapters cover linear equations (reciprocal matrices), eigen-values and eigen-vectors and a discussion of computational techniques appropriate to both topics. (Here the difficulties of presentation are by no means inconsiderable and it is very much to the credit of the authors that they managed to overcome them so suecessfully.)

The book, which can be recommended unreservedly as a basis of an excellent introductory courso for third-year and postgraduate students, is well produced and very reasonable in price.

P. A. LINDSAY

\section{Comparative Physiology and Pathology of the Skin}

Edited by A. J. Rook and G. S. Walton. Pp. xiv +794 (Oxford : Blackwell Scientific Publications, 1965.) 1555.

$\mathbf{T}$ is all too easy for the physician to forget that species other than Homo sapiens contribute much more to medicine than their role as experimental animals for drug testing and similar procedures. Other species have their own physiology and pathological disorders, from which a very great deal of information of value to the study of human disease can be learnt, and this is as true of the skin. as it is of other organs.

Schwartzman and Orkin's book, Skin Diseases of Dog and Man, has aroused a lot of interest since it was published in 1962, and now Rook and Walton have edited an excellent volume, Comparative Physiology and Pathology of the Skin, incorporating the proceedings of a symposium held in Cambridge in April 1964.

The contributors include a wide range of veterinarians, biologists, dermatologists and other scientists. The book is divided into sections dealing with comparative dermatology, hair, nutritional infuences, porphyria and light, sensitization, the mast cell, immurology and tumours of the skin.

The standard of the contributions in the various chapters is almost always quite outstandingly high; as indeed one rnight expect from the very distinguished contributors. Each appears to have given of his best. Individual readers will naturally find particular sections of special interest to themselves.

Of great merit is the style in which the text is written, a tribute to the authors and editors. It is entirely intelligible to the average reader not working in the specialized field, and so provides a good guide to the interests of other workers.

I find it impossible to give other than the highest praise to the contributors and editors of this book and to the School of Clinical Research and Postgraduate Medical Teaching, and to the Veterinary Medical School of the University of Cambridge who were responsible for arranging the symposium.
C. D. CAINAN 